\title{
Pediatrik Suprakondiler Humerus Kırıklarında Açık Redüksiyon ve Perkütan Pinleme İle Kapalı Redüksiyon ve Perkütan Pinleme Sonuçlarının Karşılaştırılması
}

Comparison of Open Reduction with Percutaneous Pinning and Closed reduction with Percutaneous Pinning Results in Pediatric Supracondylar Humerus Fractures

\author{
${ }^{2}$ Sakarya Eğitim ve Araştırma Hastanesi, Ortopedi ve Travmatoloji Kliniği, Sakarya, Türkiye \\ Yazışma Adresi / Correspondence: \\ Mümin Karahan \\ Adnan Menderes Caddesi Sağlık Sokak No: 195 Adapazarı \\ T: + $902648884000 \quad$ E-mail : karahanli_190@hotmail.com \\ Geliṣ Tarihi / Received : 08.04.2021 Kabul Tarihi / Accepte: 03.05.2021 \\ Orcid : \\ Ahmet Çağrı Uyar https://orcid.org/0000-0002-8905-6320 \\ Mümin Karahan https://orcid.org/0000-0002-2137-2634 \\ Ahmet Taha Bitlis https://orcid.org/0000-0002-0459-8367 \\ Ulaş Seraslan https://orcid.org/0000-0002-6693-9737 \\ ( Sakarya Tip Dergisi / Sakarya Med J 2021, 11(2):347-352 ) DOI: 10.31832/smj.911539
}

Ahmet Çağrı Uyar ${ }^{1}$, Mümin Karahan², Ahmet Taha Bitlis ${ }^{1}$, Ulaş Serarslan ${ }^{1}$

${ }^{1}$ Sağlık Bilimleri Üniversitesi Kocaeli Derince Eğitim ve Araştırma Hastanesi, Ortopedi ve Travmatoloji Kliniği, Kocaeli, Türkiye

$\ddot{O z}$

Amaç Çalışmamııın amacı kliniğimizde suprakondiler humerus kırı̆ı̆ tanısı alarak cerrahi olarak tedavi edilen ve cerrahi sonrası poliklinik takibi yapılan hastalardan açık ve kapalı redüksiyon uygulananların tedavi sonuçlarının retrospektif olarak değerlendirilmesi ve karşılaştırlmasııdır.

Gereç ve 2014 -2020 tarihleri arasında kliniğimizde suprakondiler humerus kırı̆ı̆ tanısı ile cerrahi tedavi uygulanmış 2-10 yaş arası çocuklar değerlendirmeye alındı. Kurık

Yöntem redüksiyonu kapalı uygulanan (Grup 1) ve açı uygulanan (Grup 2) olarak iki gruba ayrılan hastaların klinik ve radyolojik sonuçları retrospektif olarak değerlendirildi. Bu değerlendirme için Flynn kriterleri kullanıldı. Krrıkların sinflandırılmasında Gartland sınıflandırması kullanıldı.

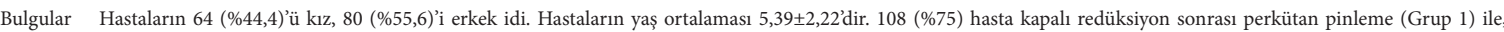
$36(\% 25)$ hasta açık redüksiyon ile perkütan pinleme (Grup 2) tekniğgi ile tedavi edildi. Yapılan istatistiksel değerlendirmede; gruplar arasinda Flynn kriterleri-kozmetik faktörler yönünden anlamlı farklllık bulunmuștur(p=0,004). Grup 2'de kozmetik faktörün orta-kötü olma sıklı̆̆ı \% 13,9 iken, Grup l'de \%0,9 dur. Gruplar arasinda "FlynnFonksiyonel faktör" yönünden incelendiğinde aralarında anlamlı fark bulunamamıștır ( $\mathrm{p}=0,057)$.

Sonuç Suprakondiler humerus kıriklarının tedavisinde amaç dirsek eklem hareket açılı̆̆̆ııı tam olarak sağlamak, nörovasküler yaralanmaların önüne geçerek fonksiyonel ve kozmetik açıdan mükemmel sonuçlar elde etmektir. Açık redüksiyonun komplikasyonlarından kaçınmak bakımından ilk tercih kapalı redüksiyon ve perkütan fiksasyon olmasına karșın kapalı redüksiyon sağlanamayan kırıklarda açık redüksiyon uygulanabilir. Uygun kırık redüksiyonu sağlanarak stabil kırık tespiti yapıldığında her iki yaklaşımda da sonuçlar benzer ve tatminkardır.

Anahtar Suprakondiler humerus;Pediatrik kırklar; Redüksiyon

Kelimeler

Abstract

Objective The aim of our study is to retrospectively evaluate and compare the treatment results of patients who underwent open and closed reduction among the patients who were diagnosed with supracondylar humerus fractures and treated surgically and were followed up in the outpatient clinic after surgery.

Materials Children, aged 2-10 years, who underwent surgery with the diagnosis of supracondylar humerus fracture between 2014 and 2020 were evaluated. The clinical and radiological results of the

and methods patients who were divided into two groups as closed fracture reduction (Group 1) and open (Group 2) were retrospectively evaluated. Flynn criteria were used for this evaluation. Gartland classification was used for the classification of the fractures.

Results $64(44.4 \%)$ of the patients were female and 80 (55.6\%) were male. The average age of the patients was $5.39+-2.22 .108$ (75\%) patients were treated with percutaneous pinning (Group 1$)$ after closed reduction, $36(25 \%)$ patients were treated with open reduction and percutaneous pinning (Group 2) technique. A statistically significant difference was found between the groups in terms of Flynn criteria-cosmetic factors ( $p=0.004)$. The frequency of having moderate-severe cosmetic factor in Group 2 was $13.9 \%$, while it was $0.9 \%$ in Group 1 . When the groups were examined in terms of "Flynn-Functional factor", no significant difference was found between them $(p=0.057)$.

Conclusion The aim of the treatment of supracondylar humerus fractures is to provide full range of motion of the elbow joint and to achieve excellent functional and cosmetic results by preventing neurovascular injuries. Although the first choice in treatment is closed reduction and percutaneous fixation, open reduction can be applied in fractures where closed reduction cannot be achieved. When stable fracture fixation is made with appropriate fracture reduction, the results are similar and satisfactory in both approaches.

Keywords Supracondylar humerus; Pediatric fractures; Reduction 


\section{GIIRIş}

Suprakondiler humerus kırıkları en sık karşılaşılan çocukluk dönemi kırıklarıdır ve genellikle 3-10 yaşlar arasında görülmektedir. ${ }^{1,2,3}$ Çocuklarda dirsek çevresi kırıklarının yaklaşık olarak \%50'sini oluşturmaktadır. ${ }^{1}$ Genel olarak açık el üzerine düşme sonrası ekstansiyon tipi kırık olurken nadiren fleksiyonda dirsek üzerine düşme ile fleksiyon tipi kırıklar oluşur. Suprakondiler humerus kırıklarında en sık kullanılan sınıflandırma Gartland sınıflandırmasıdır., Bu sınıflandırma kırıkları üç tipe ayırmaktadır; Tip1 non deplase kırıkları, tip 2 posterior korteksin sağlam olduğu ve farklı derecelerde açılanması olan kırıkları, tip 3 ise kortikal devamlılığın tamamen bozulduğu kırıkları tanımlamaktadır. ${ }^{5}$ Bu kırıklarda, hasta ilk görüldüğünde nörolojik ve vasküler muayene yapılması önemlidir. Suprakondiler humerus kırıklarının tedavisinde nondeplase (Gartlant Tip 1) kırıklar ve açılanması fazla olmayan Gartlant Tip 2 kırıklar konservatif olarak tedavi edilebilmektedir. Açılanması fazla olan Gartlant Tip 2 kırıklar ve Gartlant Tip 3 kırıklarda ise cerrahi tedavi tercih edilmektedir. ${ }^{6}$ Suprakondiler humerus kırıklarının cerrahi tedavisi ortopedi uzmanlarının günlük pratiğinde sıkça uygulanmasının yanında, tercih edilecek cerrahi yöntem ile ilgili redüksiyonun açık ya da kapalı yapılması, pin konfigürasyonu gibi durumlar klinik tecrübeye göre farklılık göstermektedir. $2,6,7,8,9,10$

Pediatrik suprakondiler humerus kırıklarında nörolojik ve vasküler yaralanmalar, kompartman sendromu, enfeksiyon, kontraktür gelişmesi, kübitus varus, kübitus valgus deformiteleri gibi komplikasyonlar görülmektedir. ${ }^{11}$

Çalışmamızın amacı kliniğimizde suprakondiler humerus kırığı tanısı alarak cerrahi olarak tedavi edilen ve cerrahi sonrası poliklinik takibi yapılan hastalardan açık ve kapalı redüksiyon uygulananların tedavi sonuçlarının retrospektif olarak değerlendirilmesi ve karşılaştırılmasıdır.

\section{GEREÇ ve YÖNTEMLER}

2014 -2020 tarihleri arasında kliniğimizde suprakondiler humerus kırığı tanısı ile tedavi edilen hastalar değerlendirildi. Çalışmaya 2-10 yaş arasında olan ve cerrahi tedavi uygulanan hastalar dahil edildi. Bu yaş aralığında olmayan ve konservatif tedavi edilen hastalar çalışmaya dahil edilmedi. Takibe gelmeyen ve hastane veri sisteminde verilerinde eksiklik olan hastalar da çalışmadan hariç tutuldu. Kırık redüksiyonu kapalı uygulanan (Grup 1) ve açık uygulanan (Grup 2) olarak iki gruba ayrılan hastalar, yaş, cinsiyet, kırık tipi, uygulanan cerrahi yöntem, hastanede kalış süresi, erken dönem komplikasyonlar, takip süresi, malunion olup olmaması, dirsek taşıma açısı değişimi ve Flynn skorları bakımından retrospektif olarak değerlendirildi. Kırıkların sınıflandırılmasında Gartland sınıflandırması kullanıldı.

Tüm hastalar cerrahi uygulanması sonrasinda uzun kol ateli ile takip edildi. 4-6 haftada yeterli kaynama tespit edilen hastalarda pinler çekilerek atel çıkarıldı ve hareket başlandı. Hastalar direkt radyografi ile malunion açısından değerlendirildi. Gonyometre ile sağlam taraf ile karşılaştırma yapılarak eklem hareket açıklıkları ve dirsek taşıma açıları kaydedildi. Fonksiyonel ve kozmetik açıdan değerlendirme için Flynn kriterleri kullanıldı (Tablo 1).

\begin{tabular}{|l|c|c|c|}
\hline Tablo 1 : Flynn kriterleri & $\begin{array}{c}\text { Fonksiyonel } \\
\text { faktör } \\
\text { Hareket } \\
\text { Sonuç }\end{array}$ & \multicolumn{3}{|c|}{$\begin{array}{c}\text { Kozmetik faktör } \\
\text { Taşıma açısı kaybı (derece) }\end{array}$} & $\begin{array}{c}\text { Hçılığı kaybı } \\
\text { (derece) }\end{array}$ \\
\hline \multirow{3}{*}{ Tatmin edici } & Mükemmel & $0-5$ & $0-5$ \\
\cline { 2 - 4 } & İyi & $6-10$ & $6-10$ \\
\cline { 2 - 4 } & Orta & $11-15$ & $11-15$ \\
\hline $\begin{array}{l}\text { Tatmin edici } \\
\text { olmayan }\end{array}$ & Kötü & $>15$ & $>15$ \\
\hline
\end{tabular}

Çalışma kesitsel tipte tanımlayıcı bir araştırmadır. Çalışmanın etiği Sağlık Bilimleri Üniversitesi Koceli Derince Eğitim ve Araştırma Hastanesi Klinik Araştırmalar Etik Kurulu'ndan 24.09.2020 tarihinde ( 2020-109 protokol numarası) alınmıştır. Çalışmamız Helsinki Deklarasyonu’na uygun şekilde yürütülmüştür. Hastane arşivinde kayıtlı 
verilerinde eksikliği bulunan hastalar değerlendirme dişı bırakıldı. Çalışmada tanımlayıcı istatistiklerden sürekli değişkenler için ortalama, ortanca, standart sapma, 1.çeyreklik, 3.çeyreklik kullanılırken, kategorik değişkenler için sayı (n) ve yüzde (\%) kullanılmıştır. Sürekli Değişkenler Normallik testlerinden Shapiro-Wilk Testi kullanılarak normalliği sınanmıştır. Sürekli değişkenler analiz edilirken normallik testine uymadığından Mann-Whitney $U$ testi kullanılmıştır. Kategorik değişkenler karşılaştırılırken Yates düzeltmeli Ki-kare testi, Fisher'nn kesin testi ve Exact metot kullanılmıștır. Kategorik değişkenlerde $\mathrm{R}^{\star} \mathrm{C}$ tablolarda beklenen değer 5 'in altında olan kutu sayısı,toplam kutu sayısının \%20'sinden fazla olduğu durumlarda , birleştirme verilerde kayba sebep olacağından Metha ve Patel'in, Fisher's exact testini $\mathrm{R}^{\star} \mathrm{C}$ tablolara uyarlayarak geliştirdikleri Exact metot kullanılmıştır. İstatiksel anlamlılık düzeyi p<0,05 alınmıştır. Veriler Analizler için SPSS v20.0 (IBM SPSS Statistics for Windows, Version 20.0; Armonk, NY, USA) paket programı kullanılmıştır.

\section{BULGULAR}

Çalışmaya toplamda 144 hasta dahil edildi. Hastaların 64(\%44,4)'ü kız, 80(\%55,6)'i erkek idi. Hastaların yaş ortalaması 5,39 $\pm 2,22$ 'dir. Hastaların \%23,6 ( $\mathrm{n}=34)^{\prime}$ 'sinda Gartland Tip 2 kırık mevcut iken, \%76,4 (n=110) Gartland tip 3 kırık mevcuttu. 2 hastada cerrahi tedavi öncesi distal nabızlar alınamadı; açık cerrahi sonrası distal ekstremite dolaşımı normale döndü. 108(\%75) hasta kapalı redüksiyon sonrası perkütan pinleme(Grup 1) ile, 36(\%25) hasta açık redüksiyon ile perkütan pinleme (Grup 2) tekniği ile tedavi edildi. Pin konfigürasyonu; $105(\% 72,9)$ hastada iki lateral-bir medial, $28(\% 19,5)$ hastada iki lateral, 11 $(\% 7,6)$ hastada bir lateral bir medial şeklinde uygulanmışt1. Hastaların hastanede kalış süreleri ortalama 1,14 (1-2) gün, ortalama takip süreleri 17,2 (12-36) aydır. Hastaların

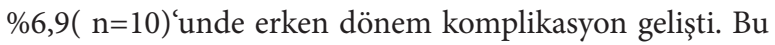
hastaların 8'inde pin dibi enfeksiyonu gelişti ve medikal tedavi ve pansuman ile iyileşti. 2 hastada postoperatif ulnar nöropraksi gelişti ve her iki hastada da postoperatif 3. ayda tam iyileşme gözlendi. Hastaların \%86,1 ( $\mathrm{n}=124)$ 'inde taşma açısı farkı yokken \%13,9'unda (n=20) taşma açısı farkı vardı. Hastaların \%4,2 ( $\mathrm{n}=6$ )'sinde varus deformitesi, $\% 2,1(\mathrm{n}=3)$ 'inde valgus deformitesi mevcuttu. Flynn fonksiyonel skoru $3(\% 2,1)$ hastada kötü, $12(\% 8,3)$ hastada orta, $4(\% 2,8)$ hastada iyi, $125(\% 86,8)$ hastada mükemmel olarak değerlendirildi. Flynn kozmetik skoru $2(\% 1,4)$ hastada kötü, $4(\% 2,8)$ hastada orta, $14(\% 9,7)$ hastada iyi, 124 $(\% 86,1)$ hastada mükemmel olarak değerlendirildi (Tablo 2).

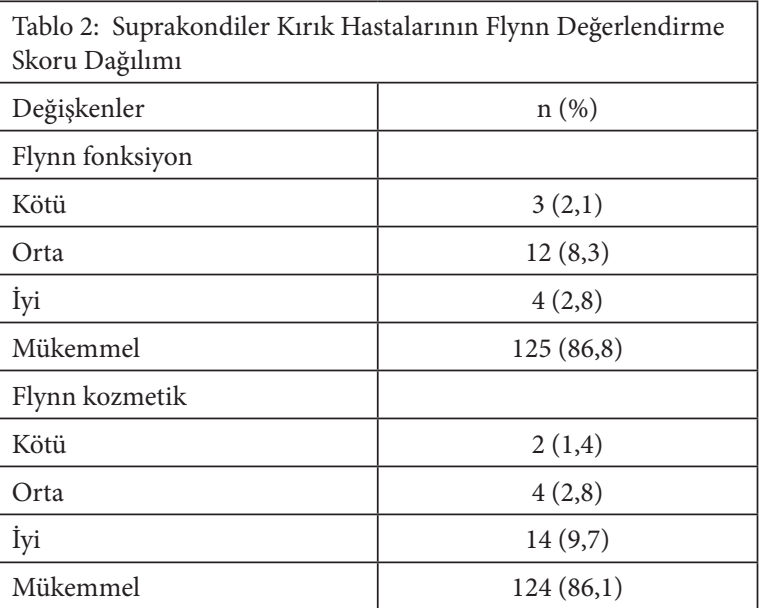

Yapılan istatistiksel değerlendirmede; grup 1 ve grup 2 arasında kırık tipi dağlımı bakımından anlamlı farklılık bulunmadı $(p=0,365)$. Yaş ve cinsiyet ile ilgili karşılaştırmada gruplar arasında anlamlı farklılık yoktu. Hastanede kalış süreleri bakımından gruplar arasında anlamlı farklılık bulunmadi $(\mathrm{p}=0,101)$. Erken dönem komplikasyon varl1ğ 1 bakımından yapılan karşılaştırmada istatistiksel olarak anlamlı fark bulunmadı( $\mathrm{p}=0,730)$. Taşıma açısı değişimi yönünden incelendiğinde gruplar arasında anlamlı farklılık bulunmadi $(\mathrm{p}=0,164)$. Malunion yönünden yapılan incelemede gruplar arasında anlamlı farklılık bulunma$d_{1}(p=0,691)$. Gruplar arasında Flynn kriterleri-kozmetik faktörler yönünden yapılan değerlendirmede istatistiksel olarak anlamlı farklılık bulunmuştur $(\mathrm{p}=0,004)$. Grup 2'de kozmetik faktörün orta-kötü olma sıklığı \%13,9 iken, Grup 1'de \%0,9'dur (Tablo 3). 
Tablo 3.Suprakondiler Kırık Hastalarına Uygulanan Müdahale Tipine Göre Flynn Kozmetik Durumlarının Karşılaştırılması

\begin{tabular}{|l|l|c|c|c|}
\hline \multirow{2}{*}{ Değişkenler } & \multicolumn{2}{|c|}{ Flynn Kozmetik Faktör } & \multirow{2}{*}{$\mathrm{p}$} \\
\cline { 3 - 4 } & $\begin{array}{c}\text { Kötü-Orta } \\
\mathrm{n}(\%)\end{array}$ & $\begin{array}{c}\text { İyi- } \\
\text { Mükemmel } \\
\mathrm{n}(\%)\end{array}$ & \\
\hline \multirow{2}{*}{$\begin{array}{l}\text { Müdahale } \\
\text { tipi }\end{array}$} & $\begin{array}{l}\text { Grup } \\
\text { 1(Kapalı) }\end{array}$ & $1(0,9)$ & $107(99,1)$ & \multirow{0}{*}{, $\mathbf{0 0 4}^{*}$} \\
\cline { 2 - 4 } & $\begin{array}{l}\text { Grup } \\
\text { 2(Açı) }\end{array}$ & $5(13,9)$ & $31(86,1)$ & \\
\hline \multicolumn{2}{|l|}{${ }^{*}$ Fisher'ın kesin testi kullanıldı. } & \\
\hline
\end{tabular}

Gruplar arasında "Flynn-Fonksiyonel faktör" yönünden incelendiğinde aralarında anlamlı fark bulunamamıştır $(\mathrm{p}=0,057)$ (Tablo 4).

\begin{tabular}{|c|c|c|c|c|}
\hline \multirow{2}{*}{\multicolumn{2}{|c|}{ Değişkenler }} & \multicolumn{2}{|c|}{ Flynn Kozmetik Faktör } & \multirow[b]{2}{*}{$\mathrm{p}$} \\
\hline & & Kötü-Orta & & \\
\hline \multirow{2}{*}{$\begin{array}{l}\text { Müdahale } \\
\text { tipi }\end{array}$} & $\begin{array}{l}\text { Grup } \\
1 \text { (Kapalı) }\end{array}$ & $8(7,4)$ & $100(92,6)$ & $0,057^{*}$ \\
\hline & $\begin{array}{l}\text { Grup } \\
\text { 2(Açı) }\end{array}$ & $7(19,4)$ & $29(80,6)$ & \\
\hline
\end{tabular}

Hastalarda uygulanmış olan farklı pin konfigürasyonları Flynn kriterleri, fonksiyonel ve kozmetik faktörler yönünden değerlendirildiğinde istatistiksel olarak anlamlı farklllk tespit edilmedi $(\mathrm{p}=1,000)$. Malunion, eklem hareket açıklıkları ve erken dönem komplikasyonlar yönünden değerlendirildiğinde pin konfigürasyonu ile ilgili anlamlı bir farklılık görülmemiştir.

\section{TARTIŞMA}

Suprakondiler humerus kırıkları çocuklarda dirsek çevresi kırıkların yaklaşık olarak \%50'sini oluşturmaktadır., ${ }^{1,2}$ Anatomik olarak bu bölgede korteks kalınlığındaki azalma kırıklar için zemin oluşturmaktadır. ${ }^{12}$ Suprakondiler humerus kırıklarının tedavisinde amaç dirsek eklem hareket açıklığını tam olarak sağlamak, nörovasküler yaralanmaların önüne geçerek fonksiyonel ve kozmetik açıdan mü- kemmel sonuçlar elde etmektir. ${ }^{3}$ Pirone ve ark. çalışmalarında açık redüksiyon uygulanan kırıklarda \%22, kapalı redüksiyon uygulananlarda $\% 5$ kötü sonuç bildirmiştir. ${ }^{10}$ Diğer bir çalışmada kapalı ve açık redüksiyon ve perkütan pinleme uygulanan gruplar arasinda fonksiyonel ve kozmetik açıdan anlamlı farklılık bulunamamıştır. ${ }^{13}$ Başka bir çalışmada kapalı redüksiyon ve perkütan fiksasyon uygulanan hastalarda Flynn kozmetik kriterlerine göre \%93,4 mükemmel sonuç bildirilmiştir. ${ }^{3}$ Bizim çalışmamıza göre kapalı redüksiyon uygulanan grupta kozmetik olarak kötü sonuç olma olasılığı daha azdır. Kapalı redüksiyon grubunda mükemmel kozmetik sonuç oranı \%99,1'dir. Fonksiyonel sonuçlar açısından ise gruplar arasında anlamlı farklılık bulunmamıştır.

Kapalı redüksiyon ve perkütan fiksasyon sırasında ulnar sinir yaralanması görülebilmektedir. ${ }^{1,6}$ Açık redüksiyon ve perkütan pinleme yöntemiyle sinir hasarına daha az rastlamaktadır fakat açık uygulamada enfeksiyon, uzun hastanede kalış süresi ve eklem sertliği ve kozmetik sorunlar gibi dezavantajlar vardır., ${ }^{6,13}$ Literatürde benzer çalışmalarda kapalı redüksiyon ve perkütan fiksasyon uygulanan yöntemlerde ulnar sinir hasarı daha sıklıkla rastlandığı bildirilmiştir. ${ }^{2,14}$ Çalışmamızda kapalı redüksiyon uygulanan grupta ulnar sinir nöropraksisi daha sık görülmekle birlikte , gruplar arasında istatistiksel olarak anlamlı farklılık bulunmadı. Çalışmamızda gruplar arasında erken dönem komplikasyonlar yönünden de istatistiksel olarak anlamlı farklılik yoktur.

Richard ve ark. çapraz pin yerleştirilmesinin lateral iki pin yerleştirilmesinden biyomekanik olarak daha üstün olduğunu bildirmişlerdir. ${ }^{15}$ Ancak fizyolojik şartlarda her iki yöntem arasında belirgin fark olmadığı belirtilmektedir. ${ }^{1}$ Eralp ve arkadaşları çalışmalarında çapraz uygulanan fiksasyonda 3 tel kullanmanın stabiliteye katkısı olduğunu söylemişlerdir. ${ }^{16}$ Afaque ve ark. yalnızca lateral ve çapraz pinleme tekniğini karşılaştırdıkları çalışmalarında klinik ve radyolojik açıdan anlamlı farklılık bulunmadığını bildirmişlerdir. ${ }^{17}$ Dekker ve ark. yaptıkları çalışmada çapraz 
ve lateral pin uygulanan hastaları karşılaştırmış ve fonksiyonel açıdan anlamlı farklılık olmadığını bildirmişlerdir. ${ }^{18}$ Eguie ve ark. da. çalışmalarında farklı pin konfigürasyonlarında benzer sonuçlar bildirmiştir. ${ }^{19}$ Bizim çalışmamızda lateral ve medialden çapraz pin konfigürasyonu ile sadece lateralden tespit yapılan hastalar arasında yapılan karşılaştırmalarda istatistiksel olarak anlamlı farklılığa rastlanmamıştır.

Çocuk suprakondiler humerus kırıklarında malunion gelişebilmektedir. ${ }^{20}$ Varus deformitesi daha sık görülmekle birlikte erken yaşlarda genellikle kozmetik problem olarak görülürken, ilerleyen yaşlarda dirsek ağrı, instabilite ve ulnar nöropatiye sebep olabilir. ${ }^{20}$ Canales-Zamora ve ark. çocuk suprakondiler humerus kırığı komplikasyonlarını değerlendirdikleri çalışmalarında \%3,97 oranında kübitus varus, \%0,72 oranında kübitus valgus görüldüğünü bildirmişlerdir. ${ }^{21}$ Bizim çalışmamızda \%4,2 kübitus varus, \%2,1 kübitus valgus görülmiştür. Fakat gruplar arasında malunion varlığı açısından anlamlı farklılık tespit edilmemiştir.

Sonuç olarak; suprakondiler humerus kırıkları çocukluk çağının sık görülen kırıklarındandır. Gartland tip 3 kırıklar ve gartland tip 2 kırıkların bir kısmında cerrahi tedavi gerekmektedir. Açık redüksiyonun komplikasyonlarından kaçınmak bakımından ilk tercih kapalı redüksiyon ve perkütan fiksasyon olmasına karşın kapalı redüksiyon sağlanamayan kırıklarda açı redüksiyon uygulanabilir. Her iki tedavide de farklı tel konfigürasyonları uygulanabilmektedir. Uygulanacak yöntem ve tel dizilimi cerrahın tercihine bağlıdır. Uygun kırık redüksiyonu sağlanarak stabil kırık tespiti yapıldığında her iki yaklaşımda da sonuçlar benzer ve tatminkardir.

\footnotetext{
Çalışmanın etiği Sağlık Bilimleri Üniversitesi Koceli Derince Eğitim ve Araştırma Hastanesi Klinik Araştırmalar Etik Kurulu'ndan 24.09.2020 tarihinde (2020-109 protokol numarası) alınmıştır.
} 
Sakarya Tip Dergisi 2021;11(2):347-352

UYAR ve Ark., Pediatrik Suprakondiler Humerus Kirıları

\section{Kaynaklar}

1. Shrader MW. Pediatric supracondylar fractures and pediatric physeal elbow fractures. Orthop Clin North Am 2008 Apr;39(2):163-71, v. doi: 10.1016/j.ocl.2007.12.005. PMID: 18374807.

2. Erdil M,Ceylan H H,Demir N,Elmadağ N M,Bilsel K,Polat G. Pediatrik Gartland Tip 3 Suprakondiler Humerus Kırıkları Cerrahi Tedavisinde Erken Dönem Sonuçlarımız. Jinekoloji Obstetrik Pediatri ve Pediatrik Cerrahi Dergisi 2013; 5(1): 27 - 31.

3. Acar E, Memik R Surgical Treatment Results in Pediatric Supracondylar Humerus Fractures. Eurasian J Emerg Med 2020;19(1): 25-9. DOI: 10.4274/eajem.galenos.2017.74046

4. Ladenhauf HN, Schaffert M, Bauer J. The displaced supracondylar humerus fracture: indications for surgery and surgical options: a 2014 update. Curr Opin Pediatr. 2014 Feb;26(1):64-9. doi: 10.1097/MOP.0000000000000044. PMID: 24378825.

5. Heal J, Bould M, Livingstone J, Blewitt N, Blom AW.Reproducibility of the Gartland classification for supracondylar humeral fractures in children. J of Orthop Surg 2007;15:12-4.

6. Omid R, Choi PD, Skaggs DL. Supracondylar humeral fractures in children. J Bone Joint Surg Am 2008;90(5):1121-32. http://dx.doi.org/10.2106/JBJS.G.01354 PMid:18451407

7. İnan $M$, Yücel B. Çocuklarda humerus suprakondiler bölge kirıkları. Totbid Der 2008; (7)3:104-11.

8. Eren A, Özkut AT, Altıntaş F, Güven M. Çocuklarda suprakondiler humerus tip III kırıkların tedavisinde lateral ve medial girișimler ile cerrahi tedavi sonuçlarının fonksiyonel ve kozmetik açıdan karşılaş̧trılması. Acta Orthop Traumatol Turc 2005;39(3):199-204. PMid:16141725

9. Karapinar L, Sürenkök F, Öztürk H, Us MR. Immediate Closed Reduction and Percutaneous Pinning in Children with Displaced Type 3 Supracondylar Fractures of the Humerus: Investigation of 258 Cases. Joint Dis Rel Surg 2003;14(3):164-75.

10. Pirone AM, Graham HK, Krajbich JL. Management of displaced extension- type supracondylar fractures of the humerus in children. J Bone Joint Surg Am 1988;70(A):641-50. 6. Gosens T, Bongers KJ. Neurovascular complic

11. Joshi T, Koder A, Herman MJ. Staying Out of Trouble: Complications of Supracondylar Humerus Fractures. Instr Course Lect. 2019;68:357-366. PMID: 32032077.

12. Abraham E, Powers T, Witt P, Ray RD. Experimental hyperextension supracondylar fractures in monkeys. Clin Orthop Relat Res 1982;(171):309-18.
13. Hussein al-Algawy, A.A., Aliakbar, A.H. \& Witwit, I.H.N. Open versus closed reduction and $\mathrm{K}$-wire fixation for displaced supracondylar fracture of the humerus in children. Eur J Orthop Surg Traumatol 29, 397-403 (2019). https://doi.org/10.1007/s00590-018-2305-9

14. Slobogean BL, Jackman H, Tennant S, Slobogean GP, Mulpuri K. Iatrogenic ulnar nerve injury after the surgical treatment of displaced supracondylar fractures of the humerus: number needed to harm, a systematic review. J Pediatr Orthop 2010 Jul-Aug;30(5):430-6. doi: 10.1097/BPO.0b013e3181e00c0d. PMID: 20574258.

15. Reynolds RA, Mirzayan R. A technique to determine proper pin placement of crossed pins in supracondylar fractures of the elbow.Journal of Pediatric Orthopaedics 2000; 20:4 485-489.

16. Eralp L, Demirhan M, Dikici F, Önen M. Deplase humerus suprakondiler ktriklarınin tedavisinde çapraz Kirschner teli ve üç tel konfigürasyonlarının radyolojik olarak karşslaş̧trrılmast. Acta Orthop Traumatol Turc 2000;34:278-83

17. Afaque SF, Singh A, Maharjan R, Ranjan R, Panda AK, Mishra A. Comparison of clinic-radiological outcome of cross pinning versus lateral pinning for displaced supracondylar fracture of humerus in children: A randomized controlled trial. J Clin Orthop Trauma 2020 Mar-Apr;11(2):259-263. doi: 10.1016/j.jcot.2019.01.013. Epub 2019 Jan 15. PMID: 32099290; PMCID: PMC7026539.

18. Dekker AE, Krijnen P, Schipper IB. Results of crossed versus lateral entry K-wire fixation of displaced pediatric supracondylar humeral fractures: A systematic review and meta-analysis. Injury 2016 Nov;47(11):2391-2398. doi: 10.1016/j.injury.2016.08.022. Epub 2016 Aug 29. PMID: 27596688

19. Eguia F, Gottlich C, Lobaton G, Vora M, Sponseller PD, Lee RJ. Mid-term Patient-reported Outcomes After Lateral Versus Crossed Pinning of Pediatric Supracondylar Humerus Fractures. J Pediatr Orthop 2020 Aug;40(7):323-328. doi: 10.1097/BPO.0000000000001558. PMID: 32271317.

20. Vashisht S, Banerjee S. Cubitus Varus 2020 Aug 10. In: StatPearls [Internet]. Treasure Island (FL): StatPearls Publishing; 2021 Jan-. PMID: 32809529.

21. Canales-Zamora OA, Mora-Ríos FG, Mejía-Rohenes LC, Anaya-Morales A, González-Gijón OR, López-Hernández JR. Complicaciones de fracturas supracondileas humerales en niños [Complications of supracondylar humeral fractures in children]. Acta Ortop Mex 2020 Mar-Apr;34(2):91-95. Spanish. PMID: 33244908. 